\title{
Predicted benthic disturbance regimes on the Australian continental shelf: a modelling approach
}

\author{
Peter T. Harris ${ }^{1, *}$, Michael G. Hughes ${ }^{2}$ \\ ${ }^{1}$ Marine and Coastal Environment Group, Geoscience Australia, GPO Box 378, Canberra, ACT 2601, Australia \\ ${ }^{2}$ School of Geosciences, University of Sydney, Sydney, New South Wales 2006, Australia
}

\begin{abstract}
Models of seabed sediment mobilisation by waves and currents over Australia's continental shelf environment are used to examine whether disturbance regimes exist in the context of the intermediate disturbance hypothesis (IDH), whereby maximum biodiversity coincides with moderate levels of disturbance. Our study shows that it is feasible to model the frequency and magnitude of seabed disturbance in relation to the dominant energy source (wave-, tide- or cyclone-dominated shelf). Areas are mapped where the recurrence interval of disturbance events is comparable to the rate of ecological succession, which meets criteria defined for a disturbance regime. We focus our attention on high-energy, patch-clearing events defined as exceeding the Shields (bed shear stress) parameter value of 0.25 . Using known rates of ecological succession for different substrate types (gravel, sand and mud), predictions are made of the spatial distribution of a dimensionless ecological disturbance $(E D)$ index, given as: $E D=F A(E S / R I)$, where $E S$ is the ecological succession rate for different substrates, $R I$ is the recurrence interval of disturbance events and FA is the fraction of the frame of reference (surface area) disturbed. Maps for the Australian continental shelf show small patches of seafloor where ED indicates the potential existence of disturbance regimes (and inferred greater biodiversity) distributed around the continent, on both the inner and outer shelf. The patterns are different for wave-dominated (patches on the outer shelf trending parallel to the coast), tide-dominated (patches crossing the middle-shelf trending normal to the coast) and cyclone-dominated (large oval-shaped patches crossing all depths) shelf environments. Only a small portion of the shelf $(\sim 10 \%)$ is characterised by a disturbance regime as defined here.
\end{abstract}

KEY WORDS: Continental shelf $\cdot$ Physical processes · Ecological succession · Intermediate disturbance hypothesis · Disturbance regime

\section{INTRODUCTION}

Marine conservation initiatives are designed to protect biodiversity by means of including information on habitats and ecosystem processes (O'Boyle \& Jamieson 2006, Young et al. 2007, Cogan et al. 2009, Ottersen et al. 2011). As such, an understanding of the dominant disturbance-causing processes that define and characterise different benthic environments is an important factor to ensure that the full range of different environments have been identified so that they can be included in the design of conservation measures. However, even though many specialists have recognised the importance of including disturbance among the ecosystem characteristics, there are very few published examples where they have been included in management decisions (Kostylev et al. 2005, Kostylev \& Hannah 2007, Cogan et al. 2009). This is probably because our understanding of ecological disturbance is poor and 
our ability to represent disturbance processes spatially is limited.

In this paper we address some physical aspects of marine ecosystems that can be modelled and quantified to support management applications at broad (continental shelf) spatial scales. Disturbances related to near-bed currents on the continental shelf and the induced bed shear stress are assessed in terms of their capacity to cause an ecological disturbance (i.e. creating a patch of disturbed habitat). A disturbance regime exists if patch creation occurs at a recurrence interval matching the community recovery time, which in turn is different for different substrate types. Key questions we pose are: (1) what are the main physical parameters controlling the occurrence of disturbance regimes; (2) do conditions exist on the Australian shelf for the occurrence of disturbance regimes; and (3) if so, where do they occur? Knowledge of the occurrence and spatial distribution of ecosystems characterised by such disturbances is an essential prerequisite to recognising and addressing their particular management requirements.

\section{Physical disturbance of the seabed}

A fundamental tenet of ecology is that ecosystems and species evolve in response to a particular regime where environmental disturbance can play a significant role in controlling such things as life cycles, food and nutrient supply and habitat availability. A definition of ecological disturbance was provided by Pickett \& White (1985) as 'any discrete event in time that disrupts ecosystem, community or population structure and changes resources, substrate availability, or the physical environment' (i.e. alters niche opportunities for the species capable of living in a given setting). The agents of ecological disturbance can be many and varied including biotic (e.g. predation and nutrient availability), physical (e.g. wave action and temperature), chemical (e.g. dissolved oxygen and $\mathrm{pH}$ ) and anthropogenic (e.g. trawling and pollution), to list a few (e.g. Sousa 1984, Proulx \& Mazumder 1998, Svensson et al. 2007). Each of these examples occurs at multiple scales and is often contemporaneous, asynchronous and heterogeneous. These processes play a crucial role in the dynamic fluctuation of habitat availability and biotic diversity (Field 2005). In the present study, seabed disturbance is restricted to physical, wave and current processes that clear a patch, removing the benthic flora and fauna, thus producing a space available for re-colonisation.

\section{Habitat patches and the intermediate disturbance hypothesis}

When a disturbance agent creates a patch of open space, an ecological succession ensues, with different species arriving over time, until the disturbed patch finally reverts to a mature state (Connell 1978). Hence, landscapes that are subject to different disturbance agents at different times exhibit a degree of patchiness that relates to past disturbances, their colonisation by opportunists and gradual recovery. Hierarchies of patches coexist at multiple scales, created by a range of physical and biological processes (Wu \& Loucks 1995). Patchy landscapes, within a specified frame of reference and length scale, thus contain greater biodiversity per unit area than either the disturbed or undisturbed habitat alone.

The size of patches and the degree of patchiness (the number of co-existing patches of different ages) are related to the spatial scale and temporal frequency of the physical disturbance. Exposure to physical processes (specifically waves, currents and sediment transport) can cause the tearing of plants and sessile fauna from their place of attachment (Thomsen et al. 2004), mobilisation of sediment and burying of plants and animals (Aller \& Todorov 1997), interference with suspension feeding (Lohrer et al. 2006), damage to organisms by abrasion (Cheroske et al. 2000), inhibition of larvae from settling (Hutchinson \& Williams 2001) or limitation of light availability (Carruthers et al. 2002; see also review by Hall 1994). Consider tropical cyclones as an example. Modelling of shelf currents generated by these events show how cyclonic wind shear can induce a current field having depth-averaged peak flow speeds of $>2 \mathrm{~m} \mathrm{~s}^{-1}$ within $\sim 50 \mathrm{~km}$ from the eye of the storm (Hearn \& Holloway 1990, Keen \& Slingerland 1993). Such flows have been shown to mobilise the upper $1 \mathrm{~m}$ of bed sediment on the shelf and to disturb the benthos (Morton 1988, Gagan et al. 1990, Hubbard 1992). In the case of reef substrates, Van Woesik et al. (1991) described the effects of 1990 tropical cyclone Ivor on the Great Barrier Reef as including breakage and dislodgement of corals, mass movements of sediments and debris and the removal of sections of reef matrix. These levels of benthic disturbance and the size of the area over which extreme flow speeds occur suggest a potential patch size of up to $100 \mathrm{~km}$ diameter associated with tropical cyclones. Puotinen (2004) examined cyclone track information in the Great Barrier Reef extending from 1910 to 1999 and determined the temporal frequency of cyclones on a 1 degree grid over the Great Barrier 
Reef. The median frequency ranged from 1 event every 4 to $15 \mathrm{yr}$.

While the potential patch size and degree of patchiness can be estimated based on the spatial scale and temporal frequency of the disturbing agent, the actual patch size and degree of patchiness depends on several factors, such as the heterogeneity of the substrate type (particularly its shear strength), the duration and stationarity of the disturbance event, the robustness of the benthic species, and the ratio of disturbance frequency to recovery rate, to name only a few. The large number of factors that need to be considered to determine whether or not a patch has been created makes it extremely difficult to predict the patchiness in any given environment. The agents of disturbance considered here may or may not create a cleared patch of substrate suitable for recolonisation, depending on the intensity of the event in relation to the nature of the benthic community and substrate in question. Communities composed of fragile benthic animals are disturbed by events that attain a lower bed shear stress than communities of robust animals that have evolved to withstand more energetic conditions. Furthermore, different substrates are more or less susceptible to disturbance depending on hardness, biological and chemical binding, particle size, depth, bed morphology, orientation to flow and a range of other factors (see review by Hall 1994).

The framework used here for exploring ecological disturbance is the intermediate disturbance hypothesis (IDH), which proposes that habitats exposed to an intermediate level of disturbance will have maximum biodiversity. Lower levels of disturbance are associated with less biodiverse habitats dominated by the

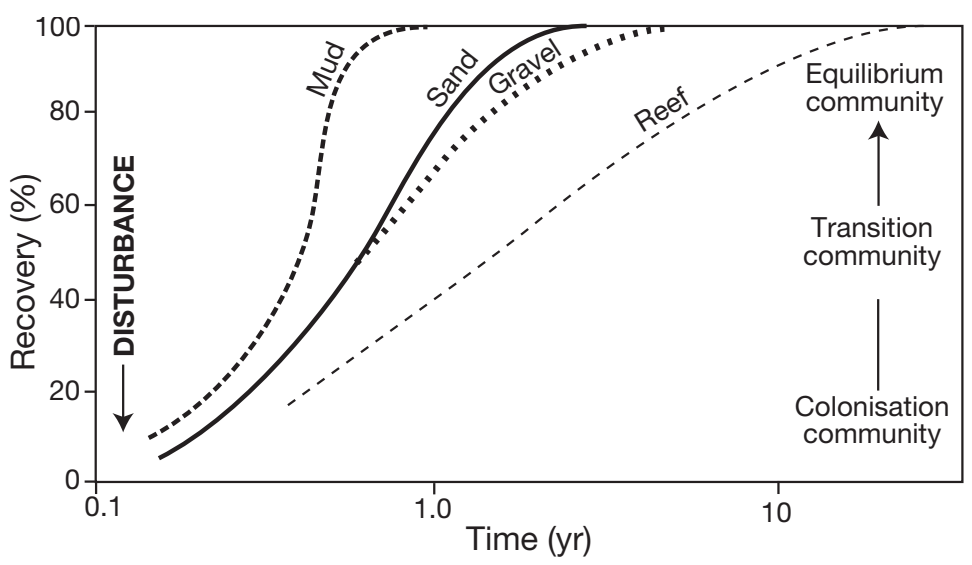

Fig. 1. Percentage recovery for different benthic communities versus time required for ecological succession of different substrate types (modified from Harris 2012) based on Newell et al. (1998) for gravel sand and mud, with reef recovery times proposed by Done (1992), Harmelin-Vivien (1994), Connell (1997) and Halford et al. (2004) relatively few species that survived competitive exclusion, whereas higher levels of disturbance are associated with less biodiverse habitats dominated by pioneer species (Grime 1973, Connell 1978, Huston 1979). Intermediate levels of disturbance of a habitat allow for the greatest diversity of species to exist, in large part through the presence of disturbed patches of varying ages and community succession. Patchy landscapes, taken as a whole, contain a greater number of species (greater biodiversity) per unit area than either the disturbed or undisturbed habitat alone (Wu \& Loucks 1995).

In order to predict ecological disturbance on the continental shelf (arising from physical stress at the seabed), the key questions to resolve are: (1) what is the time scale associated with ecological succession following patch creation; (2) what is the magnitude of bed shear stress required to create a patch in the benthic community present on an area of shelf; and (3) what are the physical shelf processes available to create patches and what is their associated frequency?

\section{Time scale of ecological succession}

After an area of seabed has been disturbed, the time required for the community to be restored to its pre-disturbance state is controlled by a number of factors, including substrate type, food availability, temperature, oxygen and the annual variability in these parameters (Kostylev et al. 2005, Kostylev \& Hannah 2007). Studies that have measured the rates of recovery of different habitats have been carried out mostly in temperate coastal environments. Newell et al. (1998) provided a conceptual summary of ecological succession rates typical of benthic communities within temperate estuaries, in which recovery periods increased from $<1$ yr for muddy substrates to several years for sandy to gravely substrates and $\sim 10$ yr for rocky, reef-type habitats (Fig. 1). The trend of different recovery times for different substrate types appears to be a consistent pattern among the case studies of ecological successions reviewed by Harris (2012), wherein shorter recovery times of $\sim 1$ yr relate to soft-sediment habitats and longer recovery times of $\sim 10$ yr relate to coral reef habitats. This suggests that the window for the period of disturbance regimes where the IDH could apply should extend from $\sim 1$ to $10 \mathrm{yr}$ for most shelf benthic communities 
(Fig. 1), although the rate of ecological succession will vary with habitat type, productivity and climate regime (see 'scope for growth' described by Kostylev et al. 2005, Kostylev \& Hannah 2007)

\section{Magnitude of bed shear stress required to clear a habitat patch}

To create a cleared patch of habitat, the current speed must attain some critical value above which the community in question cannot remain intact. Sediment transport theory can provide guidance on what level of bed stress must be exceeded to create a disturbed patch. Sediment transport only begins when the bed shear stress provides sufficient force (lift and drag) to overcome the force of gravity and any cohesive effects binding the bed sediment (Masselink \& Hughes 2003). This is usually expressed in terms of exceeding the critical bed shear stress required for sediment entrainment (Sleath 1984, Soulsby 1997). The classical work on sediment entrainment was by Shields (1936). He expressed the critical bed shear stress required to initiate sediment motion $\left(\tau_{c}\right)$ non-dimensionally as the critical Shields parameter, $\theta_{c}$ :

$$
\theta_{\mathrm{c}}=\frac{\tau_{\mathrm{c}}}{g\left(\rho_{\mathrm{s}}-\rho\right) d}
$$

where $\rho_{\mathrm{s}}$ is sediment density, $\rho$ is water density, $g$ is acceleration due to gravity and $d$ is grain diameter. However, simply mobilising the bed sediment may not be sufficient to create a cleared patch of habitat. To create a disturbance, the flow-induced bed shear stress must clear a patch of habitat through direct damage to the benthos or through abrasion, light reduction, burial or displacement by sediment transport and/or bedform migration.

Once sediment grains are in motion, wave-like features are formed on the seabed; these are known collectively as bedforms. The migration of bedforms across the seabed will produce a sequence of covering, uncovering and recovering a benthic community. Whether bedform migration is sufficient to cause a disturbance will obviously depend on the scale of the bedform relative to the scale of the species present. For example, $1 \mathrm{~cm}$ high ripple migration is not likely to disturb a patch of seagrass; in fact, ripples are commonly observed in healthy seagrass beds. The migration of large, $>5 \mathrm{~m}$ sand banks, in contrast, has been hypothesised to be responsible for the die-back of seagrass beds in Torres Strait (Daniell et al. 2008). Thus, we may infer that disturbance of the benthos is likely to occur when the sedimento- logical conditions are met for the formation and migration of large bedforms, which coincides with a Shields parameter (non-dimensional bed shear stress) value of 0.25 . This value is several times larger than that required to initiate traction bedload transport $(\sim 0.05)$ and falls in the middle of the ripple and dune bedform stability field. When $\theta_{c}$ is $>0.25$, conditions on the seabed are highly mobile and patches of disturbed habitat are likely to be created; this value is adopted as the critical threshold for the present study.

\section{Physical shelf processes available to create patches}

A current type, or combination of current types, that causes periodic or episodic disturbances meeting the IDH criteria will give rise to a disturbance regime. Tidal currents are an example of periodic flows. Plants and animals that live in tidal environments are affected by the fortnightly neap-spring cycle of the tides and are exposed to intense spring tidal currents in macrotidal environments. Tidal environments may be extremely energetic and cause intense suspended and bedload transport. However, tidal currents do not constitute an intermediate disturbance regime in the context of benthic ecology, because the recurrence interval of tides is short compared with life cycles and recruitment of benthic communities (Figs. $1 \& 2$ ). Also, because tidal currents would not be expected to create a patch of newly disturbed habitat over daily or fortnightly intervals, there are no patches of disturbed habitat present in such a high-frequency current regime. The benthos existing in a tidal environment will have adapted to the energetic reversing currents that occur twice daily (or daily in diurnal tidal systems), and they have evolved to feed and reproduce in such an environment, with different communities occurring along the gradient of tidal bed shear stress (Warwick \& Uncles 1980, Long et al. 1997).

At the opposite end of the temporal spectrum are disturbances that occur so infrequently that the processes of colonisation and re-establishment of undisturbed seafloor are only rarely present together. For the vast majority of the time there are no patches of disturbed habitat present. Examples of such currentrelated disturbances are shelves subject to tsunami or mass failures (slumps or debris flows) that occur only over centennial, millennial or geological time scales (Fig. 2).

In the case of a true disturbance regime, the physical process must be infrequent enough that the com- 


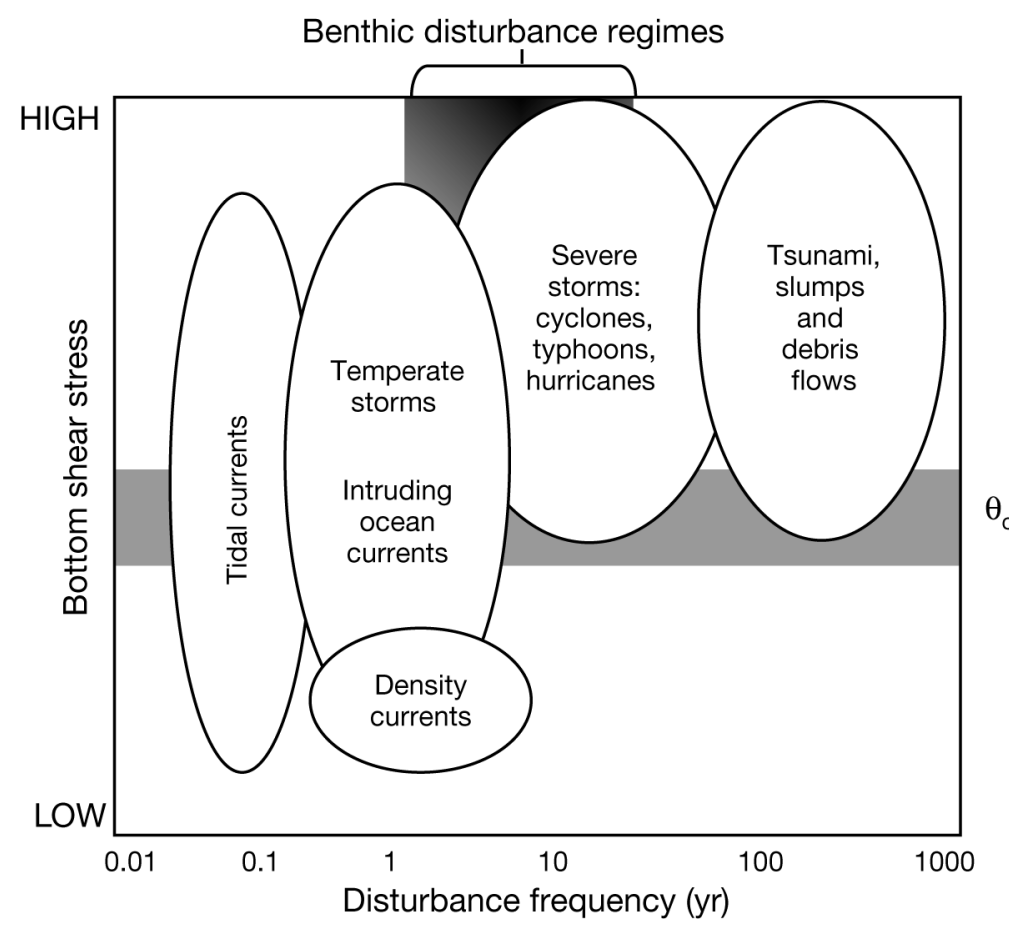

Fig. 2. Conceptual diagram showing the typical frequency and magnitude of shelf-current types in relation to those capable of causing a benthic disturbance regime by exceeding a critical level of shear stress $\left(\theta_{c}\right)$ at a typical, mid-shelf geomorphic setting (modified from Harris 2012). See 'Physical shelf processes available to create patches' for further explanation

munity is adapted to the lower energy conditions that occur between current events. For this reason, the gradation between true disturbance regimes and frequent, high-energy storm or intruding ocean current events is best viewed as a continuum rather than a distinct boundary (Fig. 2). In a similar way, the intensity of the bed stress that causes a disturbance (vertical axis, Fig. 2) is also a continuum rather than a distinct boundary because different organisms will be affected by high bed stress events in different ways. Benthic plants and animals have physical attributes that have evolved to yield some advantage for particular physical environments (Mann \& Lazier 2006). For some fragile, epibenthic plants or animals (e.g. some bryozoans and gorgonians), exceedence of the critical threshold value by any amount will be catastrophic, resulting in dislodgement, breakage and fragmentation. Other species, such as heavily calcified or massive forms (e.g. barrel sponges), deposit feeders and infauna (e.g. bivalves), are able to withstand more intense bed stress events and can recover quickly after the event is over (Hall 1994).

The process must be great enough in both magnitude and spatial extent to create a patch of habitat that is disturbed enough to create space for opportunistic species to colonise. For example, density currents formed on the continental shelf by processes that cool shelf waters and/or increase salinity are known to occur at different frequencies (Nunes Vaz et al. 1990, Williams \& Bindoff 2003). Where measurements have been made, it has been shown that such density flows on the shelf are mostly very weak $\left(\sim 10 \mathrm{~cm} \mathrm{~s}^{-1}\right)$ and are thus incapable of causing a physical disturbance of their own accord (although cascades of dense shelf water may attain much greater speeds where they descend submarine canyons; these are located on the continental slope rather than on the shelf, e.g. Canals et al. 2006). Therefore, although density currents may occur at intervals comparable to the life cycles and recruitment of benthic species, they are unlikely to cause a physical disturbance because of their low intensity (Fig. 2).

Processes that occur within the frequency range and with a great enough intensity to cause a disturbance (i.e. the upper-centre of Fig. 2) are temperate storms, the intrusion of ocean currents onto the continental shelf and severe storms. The frequency of occurrence of these high-energy events coincides with the time required by opportunistic colonisers to move in and for the patch to recover to a pre-disturbed state, resulting in patches of disturbed and undisturbed habitat to coexist.

Classification of the Australian shelf according to the principal drivers for sediment transport (Fig. 3) illustrates that a mixture of tidal currents and tropical cyclones dominate the northern half of the Australian shelf, whereas temperate storms and swell are important across the southern half. Historical tropical cyclone tracks across the Australian shelf are largely constrained between 10 and $25^{\circ} \mathrm{S}$. The cyclone season extends from December to April, with average occurrences of 1.5 and 2.5 cyclones per year for the northeast and northwest margins, respectively (Lourensz 1981). Temperate storms affect the southern margin in winter and are responsible for episodic large wave events; annual return significant wave height up to $8.7 \mathrm{~m}$ is superimposed on persistent high energy swell with a modal significant wave height of 2-3 m (Hemer et al. 2009). Intruding ocean currents onto the shelf are of minor, localised importance in the vicinity of Fraser Island (Queensland) and Exmouth (Western Australia). 


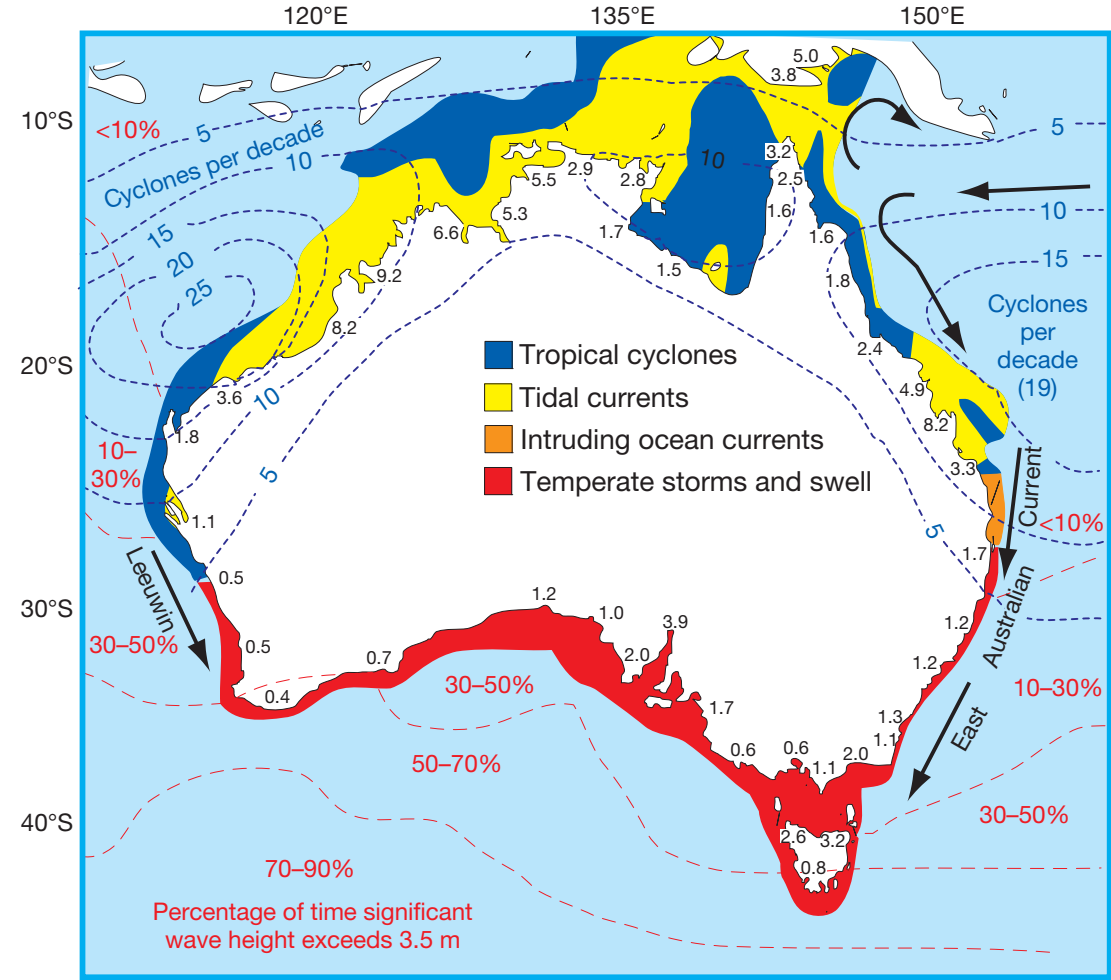

Fig. 3. Division of the Australian shelf (modified from Harris 1995) into regions in which sediment transport is caused mainly by currents derived from tropical cyclones, tidal currents, intruding ocean currents, and currents generated by storms and ocean swell. Contours of tropical cyclone frequency per decade are from Lourensz (1981) and contours for significant wave height percentage exceedance are from McMillan (1982). Mean spring tide ranges indicated along the coastline are derived from the Australian National Tide Tables. The location and direction of flow of major ocean currents are indicated rence interval $(R I)$ matching the community recovery time, which in turn is different for different substrate types (Fig. 1). Another aspect is the spatial scale of the patch-creating process and the size of patches of disturbed habitat created by an event. To account for spatial heterogeneity in both disturbance processes and substrate composition, we must define a spatial frame of reference and determine whether or not the patches of disturbed habitat created by an event are larger or smaller than the frame of reference. These concepts are fundamental to deriving any measure of habitat disturbance or the presence/absence of disturbance regimes. In order for the conditions of a true disturbance regime to be fulfilled, habitat patches of disturbed, recovering and equilibrium benthic communities must coexist within the spatial frame of reference. In other words, disturbance regimes only exist where the patches of disturbed habitat created by disturbance events occupy some fraction $(F A)$ of the spatial frame of reference. Considering these factors together (Fig. 4), we define here a dimensionless ecological distur-
Temperate and severe (tropical cyclone) storms control sediment transport over $82 \%$ of the shelf area, whereas tidal currents and intruding ocean currents are predominant over 17.4 and $0.6 \%$ of the shelf area, respectively (Porter-Smith et al. 2004). Therefore, in the context of the IDH, up to $82.6 \%$ of the Australian shelf could potentially exist under a disturbance regime that assists in maximising biodiversity.

\section{THEORY OF SHELF DISTURBANCE REGIMES}

\section{Dimensionless ecological disturbance index}

The recurrence interval of threshold-exceeding (patch-creating) bed shear stress events is considered here in relation to the ecological succession (ES) rates for different substrates (Fig. 1). An optimised disturbance regime exists (and maximum biodiversity occurs) if patch creation occurs at a recur- bance $(E D)$ index as the ratio of ecological succession and disturbance recurrence interval times the fraction of the area disturbed in any event:

$$
E D=F A \frac{E S}{R I}
$$

In the case where the frame of reference is equal to or less than the size of patches of disturbed habitat created by an event $(F A=1)$, any event will result in the complete removal of the equilibrium community within the spatial frame of reference. This does not meet the criteria for a disturbance regime because habitat patches of disturbed, recovering and equilibrium benthic communities do not coexist within the spatial frame of reference. Therefore, for a disturbance regime to exist, patches of disturbed habitat created by an event must be less than $100 \%$ of the frame of reference (FA must be fractionally less than 1).

If the disturbance recurs at the same or lesser time intervals as the rate of ecological succession (1 yr for mud, 3 yr for sand and 5 yr for gravel), then the 


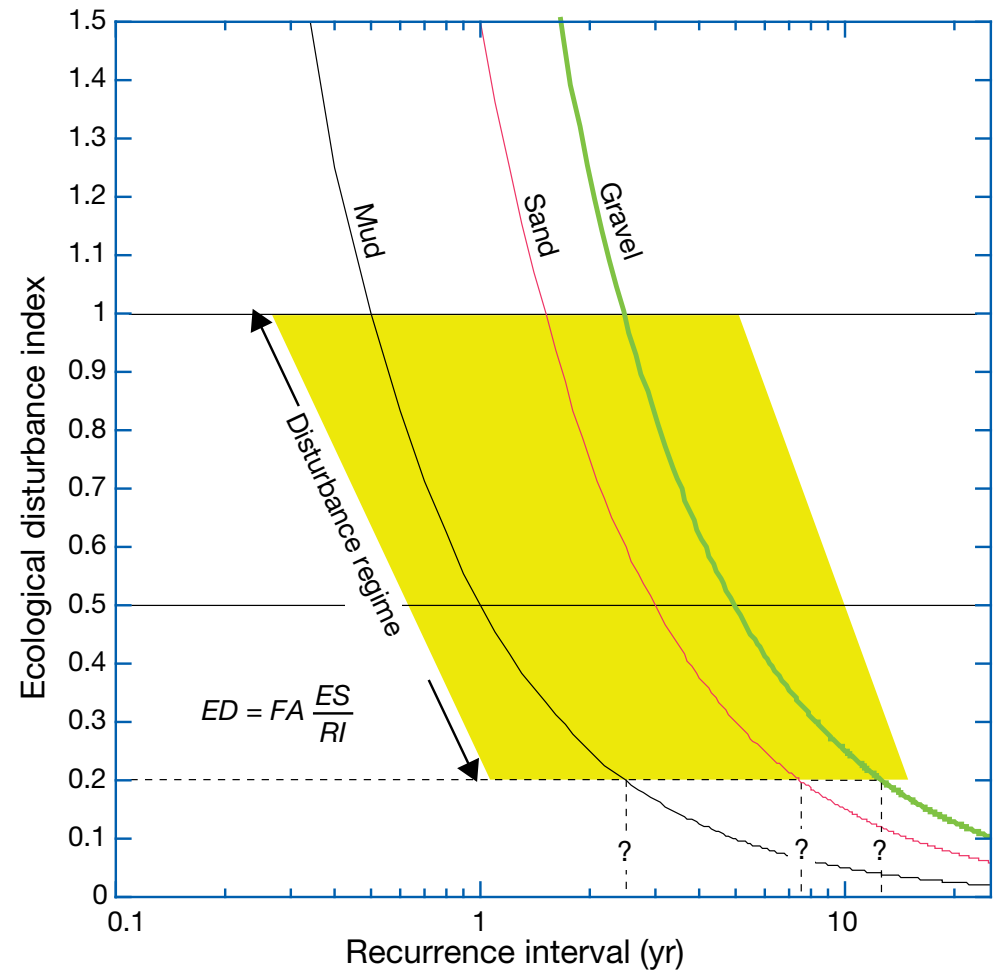

Fig. 4. Plot of ecological disturbance $(E D)$ index for mud, sand and gravel versus the log of recurrence interval $(R I)$, which is the average time in years between events where the Shields parameter exceeds 0.25 . It is assumed that these events attain sufficient shear stress magnitude to create a patch equal to $50 \%$ of the area of the chosen frame of reference (i.e. $F A=0.5$ ). Small values of $E D$ represent decreasing proportions of time when disturbed or recovering habitats are present. $E D$ values $>1$ are out of range for disturbance regimes. The lower bound for disturbance regimes occurs when $R I>>E S$ (ecological succession rate), assumed here to occur at $E D \approx 0.2$ (shown by dashed lines and?). See 'Dimensionless ecological disturbance index' for further explanation

effects of the disturbance are visible for $100 \%$ of the time and the conditions for a disturbance regime are not met. Where the recurrence interval is equal to the rate of ecological succession, the habitat will only just have completed its cycle of full recovery when the area within the frame of reference is disturbed again; the habitat occurring within the frame of reference is in a continuous state of recovery from disturbance and there is never an equilibrium community present. Hence, for conditions where $E S>R I$ (i.e. $E D$ $>1$ ), the system is outside the limits of a disturbance regime as defined in the present study (Fig. 4).

At longer $R I$ s the equilibrium community is present within our frame of reference together with recovering habitat patches. For example, at twice the time required for ecological succession, we expect the disturbed habitat with pioneers to be present for $50 \%$ of the time and the equilibrium community to be pre- sent for $50 \%$ of the time. RIs equal to 3 or 4 times the time required for $E S$ result in decreasing proportions of time when the effects of disturbance are visible (33 and $25 \%$ of the time, respectively). At increasing $R I$ s it can be seen that $E D$ is asymptotic to the $x$-axis, so $E D$ does not reach zero. At some (small) value of $E D$, however, the proportion of time that disturbed or recovering communities are present is very small compared with the amount of time that the equilibrium community is present, and we might agree that the $R I$ is too large to have any significant influence on the 'normal' state of the community. We acknowledge that this is an arbitrary boundary, but suggest that $E D \approx 0.2$ is a reasonable lower limit (Fig. 4). This equates with maximum $R I$ s of $\sim 2.5 \mathrm{yr}$ for mud, $7.5 \mathrm{yr}$ for sand and $10.5 \mathrm{yr}$ for gravel (Fig. 4).

A theoretical maximum in biodiversity will occur for $E D=0.5$, where the patch areas cleared by one or more disturbances are equal to half the area of the frame of reference. This yields equal areas of equilibrium community and disturbed/recovering patches being present at any given time. We suggest that the relative proportion of different community areas affects community biodiversity in the same way as the numbers of individuals affects evenness of the Shannon species biodiversity index: a sample of 100 individuals comprised of 50 individuals of species $X$ and 50 individuals of species $Y$ is more diverse than a sample containing 99 individuals of species $X$ and only 1 individual of species $Y$. So a frame of reference of $100 \mathrm{~km}^{2}$ composed of $50 \%$ equilibrium community and $50 \%$ pioneer community is more diverse than one composed of $99 \%$ equilibrium community and $1 \%$ pioneer community.

The effect of including the spatial fraction multiplier (FA) in Eq. (2) is to push the curves closer to the origin. This mathematical analysis ignores many complexities associated with the true heterogeneity of the seafloor which, in turn, gives rise to habitat patchiness. During a shear stress event where the Shields parameter exceeds 0.25 , a number of factors may cause some areas to become quickly stripped clear of epibenthos and others to resist damage. These factors include subtle variations in depth, local shielding behind rocky outcrops, greater or lesser efficient biological or chemical bounding of bed sediments, bedform size and migration rates, sediment 
armouring of the bed and variations in the thickness (and availability for transport) of unconsolidated sediments. Patchiness is also created by biological factors such as disease, predation, competition and different responses during reproductive events, to name a few.

In this study, our frame of reference is set by the model grid size equal to $0.1^{\circ}$ (approximately $10 \times$ $10 \mathrm{~km})$. This area $\left(100 \mathrm{~km}^{2}\right)$ is clearly small compared with the size of oceanographic processes that might disturb the seafloor, such as tropical cyclones, temperate storms or intruding ocean currents. However, because of the factors listed above, we also know that $100 \mathrm{~km}^{2}$ of seafloor is likely to possess a certain degree of heterogeneity that would result in a spatially patchy response to any disturbance event. We are not aware of any research that has measured the actual patchiness of disturbed benthic habitat resulting from a specific disturbance event. Therefore, values of $F A>0.1$ and $<1$ are assumed to be valid for the purposes of this study, whereby any disturbance event (where the Shields parameter exceeds 0.25) will remove some $(F A)$ fraction of the equilibrium community within each $100 \mathrm{~km}^{2}$ grid cell.

\section{METHODS}

\section{GEOMACS modelled bed shear stress due to waves, tides and ocean currents}

The Geological and Oceanograhic Model of Australia's Continental Shelf (GEOMACS) model used in this study is fully documented elsewhere (Hemer 2006, Hughes et al. 2010). The model has the following inputs: (1) nearbed oscillatory currents due to wind waves and swell derived from the ocean wave model (WAM) (The Wamdi Group 1988, Greenslade 2001); (2) near-bed currents due to tides from a linearised tidal model (Egbert et al. 1994); (3) near-bed currents due to wind- and density-driven circulation from the Ocean Circulation and Climate Advanced Modelling (OCCAM) ocean circulation model (Webb et al. 1998); (4) water depth from a $250 \mathrm{~m}$ bathymetric grid (Whiteway 2009); and (5) mean grain size from Geoscience Australia's sediment properties database (Passlow et al. 2005). GEOMACS uses these inputs together with a 1-dimensional wave boundary layer model (Grant \& Madsen 1986, Li \& Amos 2001) to calculate the total bed shear stress due to combined currents and waves. The GEOMACS output is an hourly time series of bed shear stress covering an 11 yr period (1 March 1997 to 28 February 2008) on a $0.1^{\circ}$ grid covering Australia's continental shelf (water depths $<300 \mathrm{~m}$ ). This GEOMACS data set is used here to spatially examine the Australian continental shelf for areas that meet the criteria for an ecological disturbance regime.

\section{Procedure to determine the $E D$ index}

At each location on the GEOMACS grid, the bed sediment is classified in terms of mean grain size as well as percent content of gravel, sand and mud. Mean grain size was used in conjunction with the GEOMACS modelled bed stress to compute a time series of the Shields parameter (Eq. 1). Grid cells were assigned to the 'gravel' class if percent gravel was $>30 \%$, and if percent gravel was $<30 \%$ they were assigned to either the 'sand' or 'mud' class depending on which had the largest percentage (cf. Folk 1974; Fig. 5). The ED index was then calculated using Eq. (2) and the appropriate value for $E S$ depending on the sediment class. Note that because of uncertainty surrounding the correct value of $F A$, it was assigned a value of unity; thus, we present

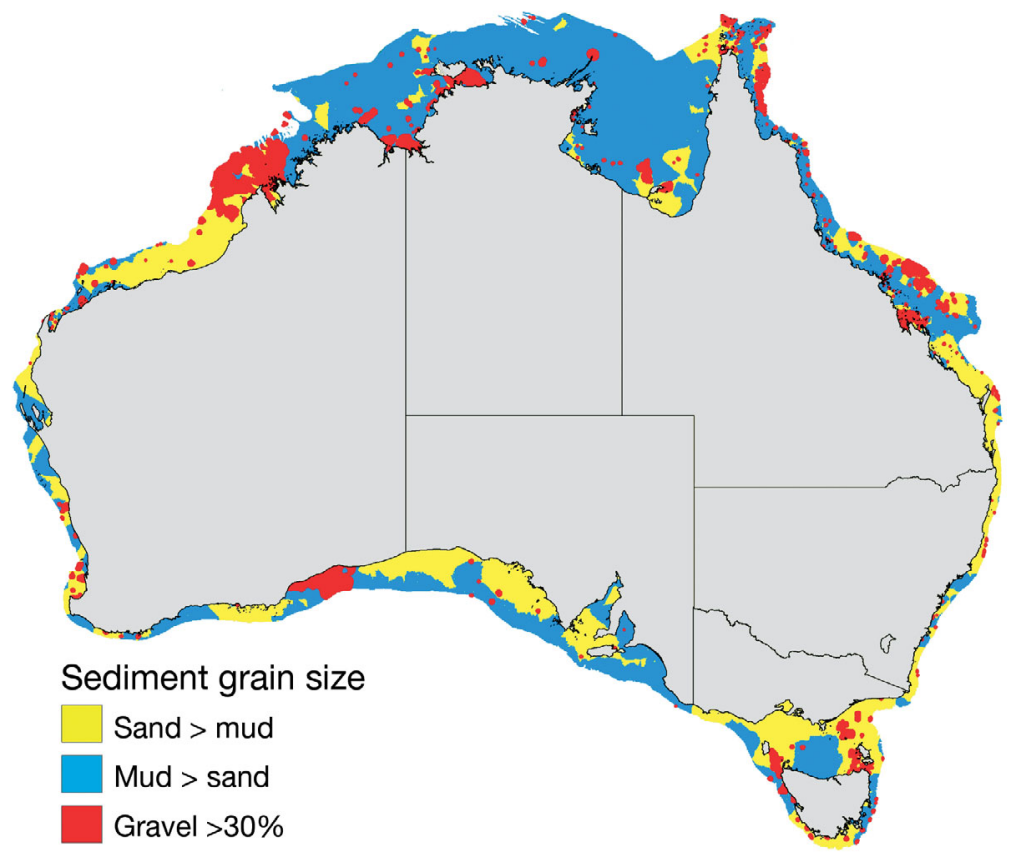

Fig. 5. Areas of gravel, sand and mud on the Australian continental shelf, derived from point measurement data $(n \approx 10000)$ stored in Geoscience Australia's Marine Sediment (MARS) database (www.ga. gov.au/oracle/mars/index.jsp) 
values for $E D$ up to 10 because they may be valid if FA assumes values as low as 0.1 .

\section{RESULTS}

In the north, the Shields parameter exceeded 0.25 for large percentages of time across almost the entire shelf width, whereas in the south the same was only true on the inner shelf (Fig. 6). The spatial pattern in this parameter is consistent with a tide-dominated northern half and wave-dominated southern half of the Australian Shelf (Fig. 3).

The amount of time between threshold events for which the Shields parameter exceeded 0.25 (Fig. 7) differed between wave- and tide-dominated areas. On wavedominated areas of the shelf it ranged from several hundred days on the outer shelf to tens of days or less on the inner shelf and close to the coastline. This spatial pattern mirrors the bathymetry and exposure to the prevailing swell direction, i.e. the minimum recurrence period between events occurred in the shallowest water depths and the coastal locations most exposed to the swell.

On tide-dominated parts of the shelf (Fig. 3), the recurrence interval between threshold events of the order 10 d or more (Fig. 7) was broadly consistent across the shelf width. Areas where the recurrence interval locally reached 100 to several hundred days were located in a broad rim around the Gulf of Carpentaria and in isolated patches across the north (Fig. 7). These areas do not necessarily coincide with the areas of greatest tidal bed stress and were therefore attributed to the wave regime.

On the cyclone-dominated (northern) parts of the continental shelf (Fig. 3), the recurrence period between threshold events was of the

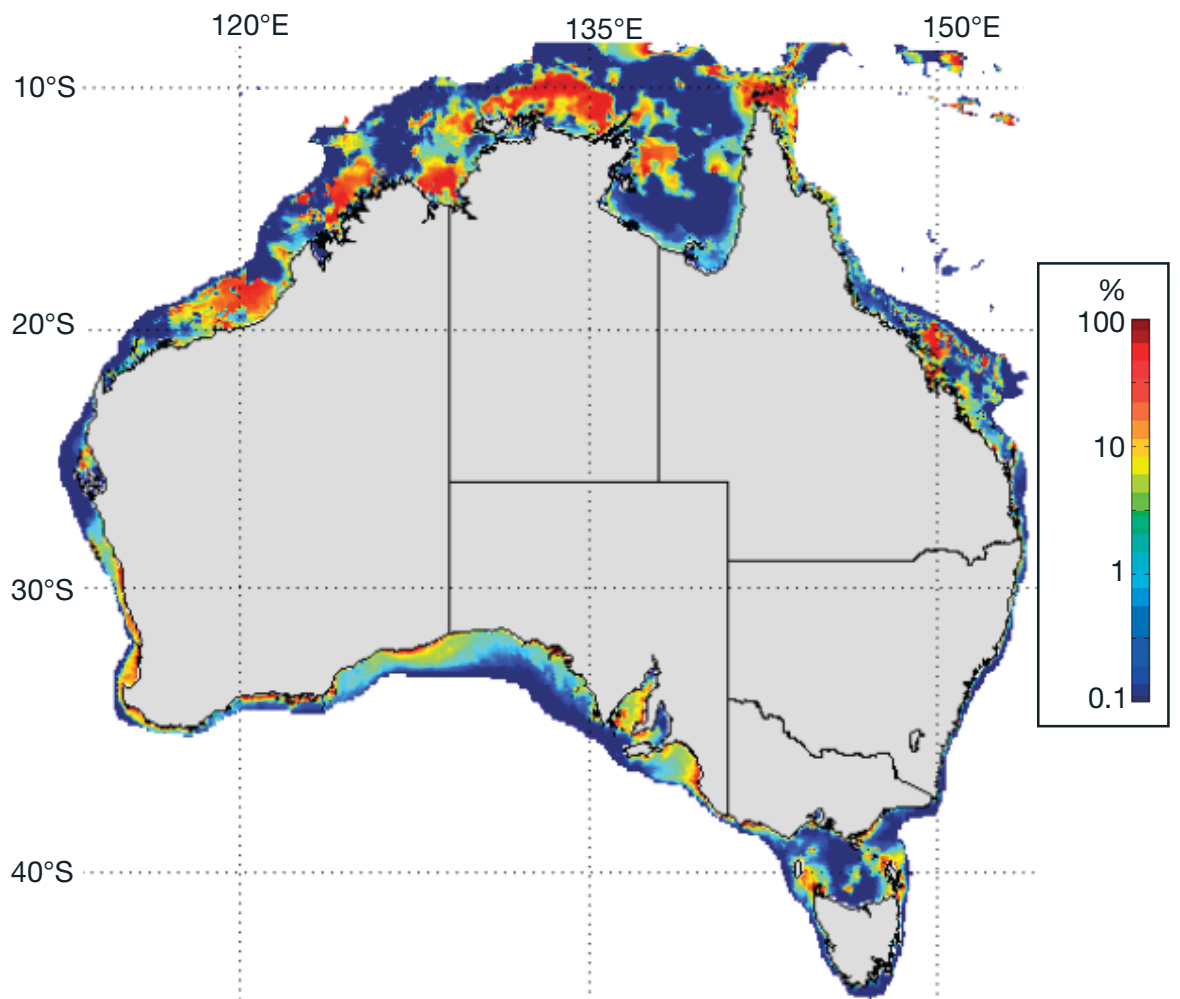

Fig. 6. Logarithm of the percentage of time that the Shields parameter exceeded 0.25 on the Australian shelf

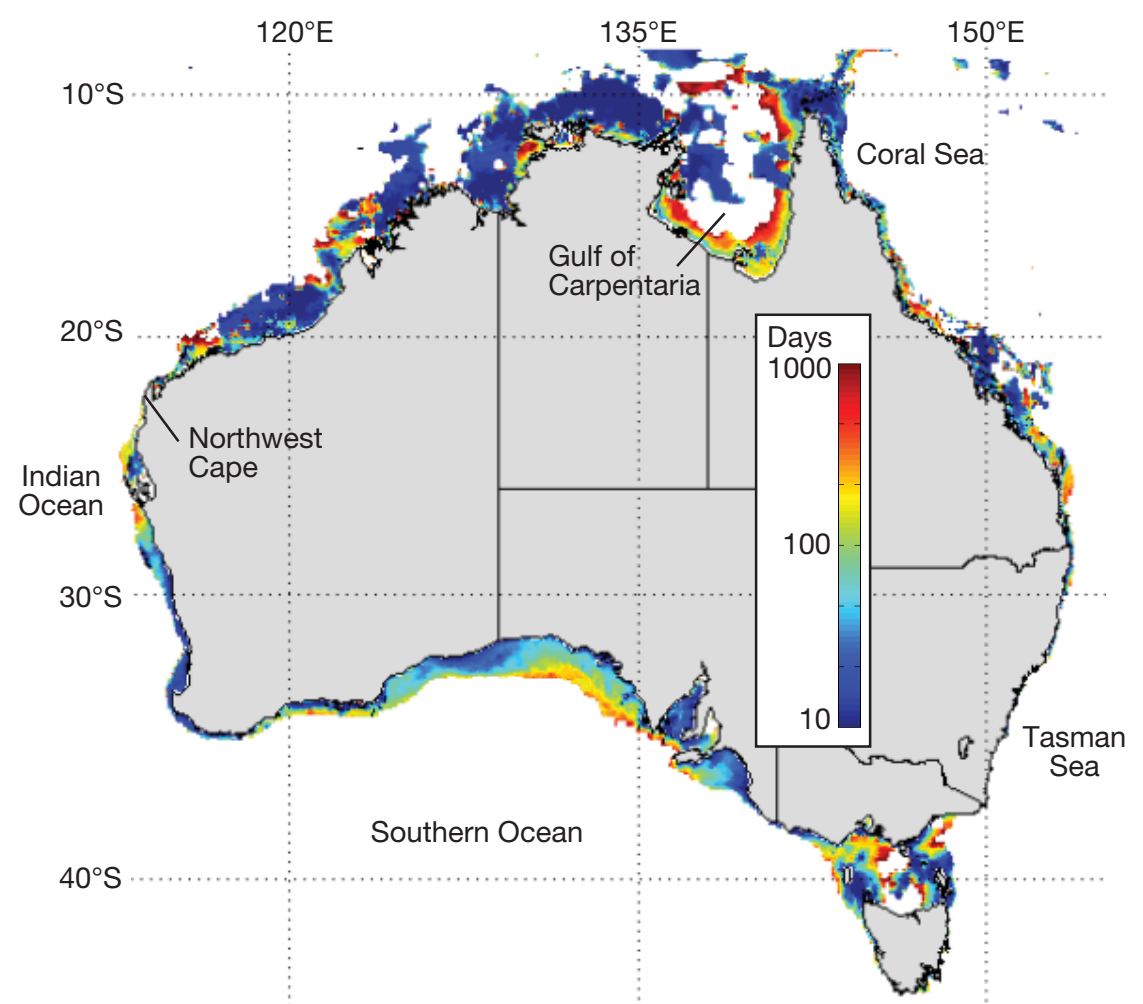

Fig. 7. Mean number of days between events for which the Shields parameter exceeded 0.25. Areas in white either did not exceed 0.25 Shields parameter during the $11 \mathrm{yr}$ time series or there was only one event that did 
order of several hundred to a thousand days across the entire shelf (Fig. 7). At the lower end of this range, south of Northwest Cape (Fig 7), seasonal swell from the southern Indian Ocean probably also contributes to the disturbance regime. In the northern part of the region east of Northwest Cape, the threshold Shields parameter is most likely only exceeded during cyclones. Cyclones impact this region on average 2.5 times a year, but the effects at any particular location are likely to be felt less frequently, depending on the precise track of the cyclone across the region.

The rate of ecological succession ( $E S$ in Eq. 2) is based on the seabed type (mud, sand or gravel) and the idealised ecological recovery rates associated with each type (1 yr for mud, $3 \mathrm{yr}$ for sand and $5 \mathrm{yr}$ for gravel; Fig. 5). Eq. (2) is thus solved by simply overlaying Figs. 5 and 7 . The result (Fig. 8) shows that most of the Australian shelf has nearzero or unrecognised (>10) ED index values. On the southern wave-dominated shelf, ED values

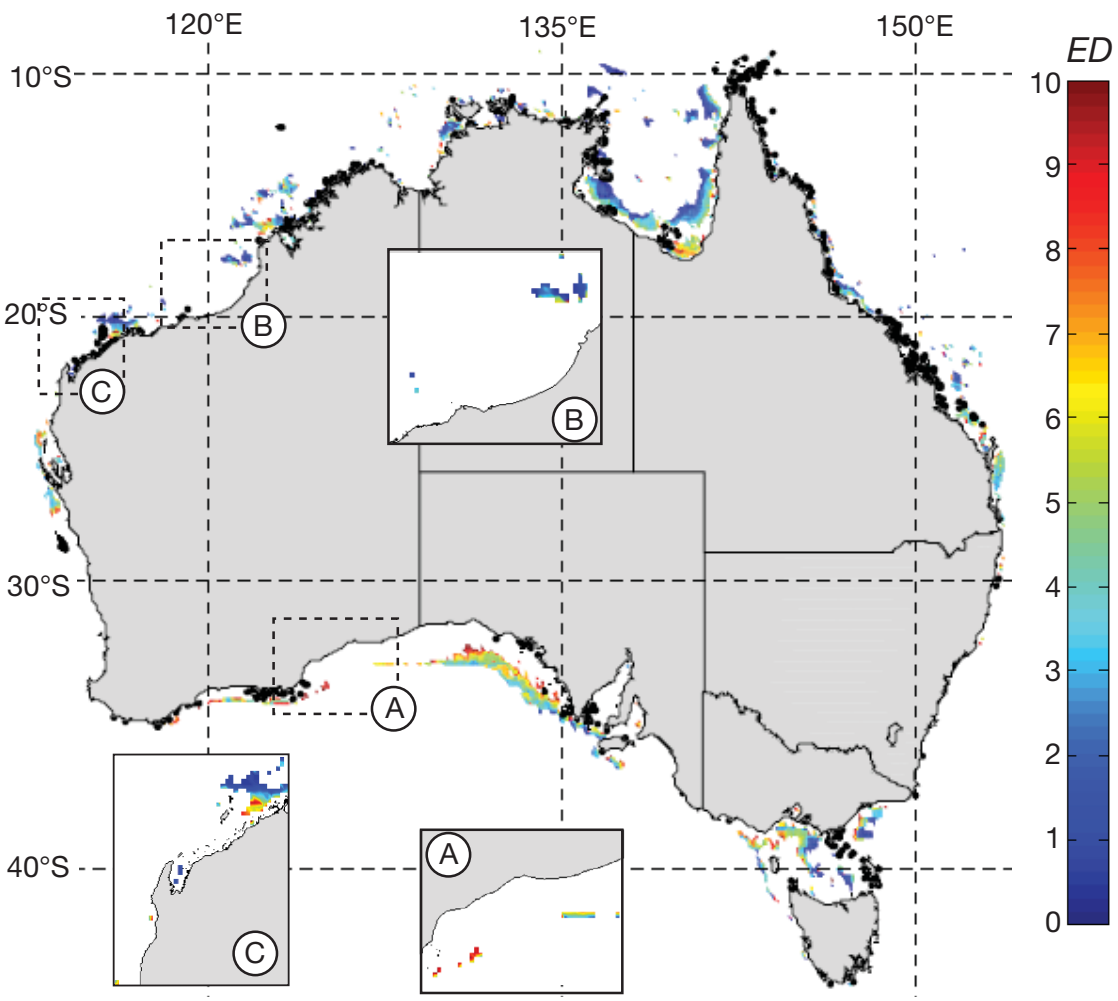

Fig. 8. Dimensionless ecological disturbance $(E D)$ index calculated for the Australian shelf. Note that the fraction of the frame of reference $(F A)=1$ was used in the calculation (see Eq. 2). White areas apply to values of $E D$ greater than 10 and less than 0.2. Example areas are: (A) wave-dominated shelf, (B) tide-dominated shelf and (C) cyclone-influenced shelf. Application of the intermediate disturbance hypothesis implies that all colour-shaded areas are expected to have greater benthic biodiversity than adjacent areas of seafloor indicative of a disturbance regime occur almost exclusively at outer shelf water depths where infrequent, very high magnitude events occur with a recurrence period matching the optimum for the local seabed sediment type (Figs. 5 \& 7). On tideand cyclone-dominated parts of the shelf, $E D$ values indicative of a disturbance regime occur in a broad band around the Gulf of Carpentaria and in isolated patches elsewhere (Fig. 8).

\section{DISCUSSION}

The pattern in ED index values (Fig. 8) is highly sensitive to the chosen threshold Shields parameter value and the local seabed type. Only a small portion of the shelf $(\sim 10 \%)$ is characterised by a disturbance regime as defined here. Within these areas, the $R I$ is comparable to $E S$ and meets our defined criteria for a disturbance regime. It follows from the IDH that all the colour-shaded areas shown in Fig. 8 are predicted to have a greater biodiversity than areas of surrounding seafloor. To our knowledge, this is the

first time such an analysis has been attempted for any continental shelf.

Managers attempting to apply ecosystem-based management concepts to the marine environment at the scale of continental shelves must depend upon models such as developed here to fill in the huge gaps that exist in biological sample databases. In particular, spatial management tools such as the design of marine protected areas depend upon access to information on the spatial distribution of biodiversity hotspots as well as the occurrence of different ecosystems and habitats. The map shown in Fig. 8 could have direct applications in this regard because the design of a marine protected area network should aim to conserve benthic biodiversity (target biodiversity hotspots) and capture different areas representative of the range of ecosystems that occur within each bioregion.

This work represents progress towards capturing the physical aspects of shelf disturbances based on sedimentological concepts by providing methods to generate ecologically meaningful regionalisations. It 
is feasible to model some of the key aspects of shelf disturbance, including the frequency and magnitude of disturbance in relation to seabed sediment size (gravel, sand or mud) and the source of disturbance (wave-, tide- or cyclone-dominated shelf). The approach of exploiting the link between modelled bed shear stress due to waves, tides and ocean currents and what is known about rates of ES for different substrate types (gravel, sand and mud) allows for maps to be derived that predict the spatial distribution of an $E D$ index.

There are many potential sources of error in deriving such maps that stem from: (1) the numerical models used to predict waves, tides and ocean currents; (2) the extrapolation of sediment type from a limited database; and (3) the rates of ES assumed. As stated in the 'Introduction', only physical disturbance of the benthos is addressed in the present study; biotic (e.g. predation and nutrient availability), chemical (e.g. dissolved oxygen, salinity and $\mathrm{pH}$ ) or anthropogenic agents, among others, were not included. In this way, our analysis of ED is conservative, in as much as the additional potential disturbance agents are potentially contemporaneous and additive in their capacity to create patches of disturbed habitat.

A useful follow-up study would be to use existing biological samples (or conduct new collection cruises, if needed) to test whether benthic biodiversity is greater within the areas predicted to exhibit disturbance regime characteristics (shown in Fig. 8) compared with adjacent shelf areas without disturbance regimes.

In order to make further progress in the modelling and prediction of disturbance regimes, we suggest attention should be focused on: (1) improved modelling of physical processes; (2) better understanding of ecological recovery rates for different habitats; and (3) better understanding of the spatial scales associated with different disturbance processes. Field studies of the spatial scale of physical disturbances caused by storms or intruding ocean currents on continental shelves are lacking and this is a major impediment to linking process studies to the design of spatial marine zone management tools. Finally, longer time-series records for disturbances are needed to characterise extreme storm events. It is important to remember that real-time estimates of disturbance 'weather' are not essential, but rather information on the long-term disturbance 'climate' is needed. This could be derived using predictive climate models, supplemented by palaeo-climate records from coral, sediment and ice-core records.

\section{CONCLUSIONS}

It is feasible to model some of the key aspects of shelf disturbance, including the frequency and magnitude of disturbance due to waves, tides and ocean currents, by extrapolating from maps of seabed bathymetry and sediment type. Fundamental components of ecological disturbance can be represented by the $E D$ index, given as:

$$
E D=F A \frac{E S}{R I}
$$

The map thus produced for the Australian continental shelf predicts that small patches having an ED between 0.2 and 1 occur, distributed around the continent, on both the inner and outer shelf, equal to $\sim 10 \%$ of the total shelf area. These results (i.e. the map of $E D$ regimes) could help managers conserve benthic biodiversity and protect different areas representative of the range of ecosystems that occur in a given bioregion. The approach used in this study could be adopted for any continental shelf region.

Acknowledgements. The authors are grateful for the support and encouragement of our colleagues in the National Environment Research Program (NERP) Marine Biodiversity Hub. Thanks to Anna Potter for assistance with drafting the gravel, sand and mud map of Australia. We are grateful for reviews of an earlier version of this paper provided by Rachel Przeslawski and Mark Pittard (Geoscience Australia). This paper is published with the permission of the Chief Executive Officer of Geoscience Australia, and the Director of the NERP Marine Biodiversity Hub.

\section{LITERATURE CITED}

Aller JY, Todorov JR (1997) Seasonal and spatial patterns of deeply buried calanoi copepods on the Amazon shelf: evidence for periodic erosional/depositional cycles. Estuar Coast Shelf Sci 44:57-66

Canals M, Puig P, de Madron XD, Heussner S, Palanques A, Fabres J (2006) Flushing submarine canyons. Nature 444:354-357

Carruthers TJB, Dennison WC, Longstaff BJ, Waycott M, Abal EG, McKenzie LJ, Lee Long WJ (2002) Seagrass habitats of north-east Australia: models of key processes and controls. Bull Mar Sci 71:1153-1169

Cheroske AG, Williams SL, Carpenter RC (2000) Effects of physical and biological disturbances on algal turfs in Kaneohe Bay, Hawaii. J Exp Mar Biol Ecol 248:1-34

Cogan CB, Todd BJ, Lawton P, Noji TT (2009) The role of marine habitat mapping in ecosystem-based management. ICES J Mar Sci 66:2033-2042

Connell JH (1978) Diversity in tropical rain forests and coral reefs. Science 199:1302-1310

Connell JH (1997) Disturbance and recovery of coral assemblages. Coral Reefs 16:S101-S113 
Daniell J, Harris PT, Hughes M, Hemer M, Heap A (2008) The potential impact of bedform migration on seagrass communities in Torres Strait, Northern Australia. Cont Shelf Res 28:2188-2202

> Done TJ (1992) Effects of tropical cyclone waves on ecological and geomorphological structures on the Great Barrier Reef. Cont Shelf Res 12:859-872

Egbert GD, Bennett AF, Foreman MGG (1994) TOPEX/ POSEIDON tides estimated using a global inverse model. J Geophys Res 99:24821-24852

Field ME (2005) Living with change: response of the seafloor to natural events. Am Fish Soc Symp 41:215-218

Folk RL (1974) Petrology of sedimentary rocks. Hemphills, Austin, TX

Gagan MK, Chivas AR, Herczeg AL (1990) Shelf wide erosion, deposition and suspended sediment transport during cyclone Winifred, central Great Barrier Reef, Australia. J Sediment Petrol 60:456-470

Grant WD, Madsen OS (1986) The continental-shelf bottom boundary layer. Annu Rev Fluid Mech 18:265-305

Greenslade DJM (2001) The assimilation of the ERS-2 significant wave height data in the Australian region. J Mar Syst 28:141-160

Grime JP (1973) Competitive exclusion in herbaceous vegetation. Nature 242:344-347

Halford A, Cheal AJ, Ryan D, Williams DM (2004) Resilience to large-scale disturbance in coral and fish assemblages on the Great Barrier Reef. Ecology 85:1892-1905

Hall SJ (1994) Physical disturbance and marine benthic communities: life in unconsolidated sediments. Oceanogr Mar Biol Annu Rev 32:179-239

Harmelin-Vivien ML (1994) The effects of storms and cyclone on coral reefs: a review. J Coast Res 12:211-231

Harris PT (1995) Marine geology and sedimentology of the Australian continental shelf. In: Zann LP, Kailola P (eds) The state of the marine environment report for Australia technical annex 1: the marine environment. Department of the Environment, Sport and Territories, Canberra, p 11-23

Harris PT (2012) On seabed disturbance, marine ecological succession and applications for environmental management: a physical sedimentological perspective. In: Li M, Sherwood C, Hill P (eds) Sediments, morphology and sedimentary processes on continental shelves. Int Assoc Sedimentol Spec Publ 44:387-404

The Wamdi Group (1988) The WAM model-a third generation ocean wave prediction model. J Phys Oceanogr 18: $1775-1810$

Hearn CJ, Holloway PE (1990) A three-dimensional barotropic model of the response of the Australian North West Shelf to tropical cyclones. J Phys Oceanogr 20:60-80

Hemer M (2006) The magnitude and frequency of combined flow bed shear stress as a measure of exposure on the Australian continental shelf. Cont Shelf Res 26: 1258-1280

Hemer MA, Church JA, Hunter JR (2009) Variability and trends in the directional wave climate of the Southern Hemisphere. Int J Climatol 30:475-491

Hubbard DK (1992) Hurricane-induced sediment transport in open-shelf tropical systems - an example from St. Croix, U.S. Virgin Islands. J Sediment Petrol 62:946-960

Hughes MG, Harris PT, Brooke BP (2010) Seabed exposure and ecological disturbance on Australia's continental shelf: potential surrogates for marine biodiversity. Geoscience Australia Record 2010/43, Canberra
Huston M (1979) A general hypothesis of species diversity. Am Nat 113:81-101

> Hutchinson N, Williams GA (2001) Spatio-temporal variation in recruitment on a seasonal, tropical rocky shore: the importance of local versus non-local processes. Mar Ecol Prog Ser 215:57-68

> Keen TR, Slingerland RL (1993) A numerical study of sediment transport and event bed genesis during Tropical Storm Delia. J Geophys Res 98:4775-4791

Kostylev VE, Hannah CG (2007) Process-driven characterization and mapping of seabed habitats. In: Todd BJ, Greene HG (eds) Mapping the seafloor for habitat characterization. Geological Association of Canada, Special Paper 47, p 171-184

Kostylev VE, Todd BJ, Longva O, Valentine PC (2005) Characterization of benthic habitat on northeastern Georges Bank, Canada. In: Barnes PW, Thomas JP (eds) Benthic habitats and the effects of fishing. Proc Symp on Effects of Fishing Activities on Benthic Habitats. Am Fish Soc Symp (Bethesda, MD) 41:141-152

Li MZ, Amos CL (2001) SEDTRANS96: the upgraded and better calibrated sediment-transport model for continental shelves. Comput Geosci 27:619-645

Lohrer AM, Hewitt JE, Thrush SF (2006) Assessing far-field effects of terrigenous sediment loading in the coastal marine environment. Mar Ecol Prog Ser 315:13-18

Long B, Bode L, Mason L, Pitcher CR (1997) Seabed current stress predicts the distribution and abundance of epibenthos in Torres Strait. Report to Australian Fisheries Management Authority. CSIRO Division of Marine Research, Cleveland, QLD

Lourensz RS (1981) Tropical cyclones in the Australian region July 1909 to June 1980. Hedges \& Bell, for the Australian Bureau of Meteorology, Maryborough, VIC

Mann KH, Lazier JRN (2006) Dynamics of marine ecosystems: biological-physical interactions in the oceans. Blackwell Publishing, Oxford

Masselink G, Hughes MG (2003) Introduction to coastal processes and geomorphology. Hodder \& Stoughton, London

McMillan JD (1982) A Global Atlas of GEOS-3 significant wave height data and comparison of the data with national buoy data. Report No. 156882, NASA, Wallops Flight Center, Wallops Island, VA

Morton RA (1988) Nearshore responses to great storms. In: Clifton HE (ed) Sedimentologic consequences of convulsive geologic events. Geol Soc Am Bull 229:1-22

Newell RC, Seiderer LJ, Hitchcock DR (1998) The impact of dredging works in coastal waters: a review of the sensitivity to disturbance and subsequent recovery of biological resources on the sea bed. Oceanogr Mar Biol Annu Rev 36:127-178

Nunes Vaz RA, Lennon GW, Bowers DG (1990) Physical behaviour of a large, negative or inverse estuary. Cont Shelf Res 10:277-304

> O'Boyle R, Jamieson G (2006) Observations on the implementation of ecosystem-based management: experiences on Canada's east and west coasts. Fish Res 79:1-12

> Ottersen G, Olsen E, van der Meeren GI, Dommasnes A, Loeng $H$ (2011) The Norwegian plan for integrated ecosystem-based management of the marine environment in the Norwegian Sea. Mar Policy 35:389-398

Passlow V, Rogis J, Hancock A, Hemer MA, Glenn K, Habib A (2005) Final report - national marine sediments database and seafloor characteristics project. Geoscience Australia Record 2005/8, Canberra 
Pickett ST, White PS (1985) The ecology of natural disturbance and patch dynamics. Academic Press, London

Porter-Smith R, Harris PT, Andersen OB, Coleman R, Greenslade D, Jenkins CJ (2004) Classification of the Australian continental shelf based on predicted sediment threshold exceedance from tidal currents and swell waves. Mar Geol 211:1-20

Proulx M, Mazumder A (1998) Reversal of grazing impact on plant species richness in nutrient-poor versus nutrientrich ecosystems. Ecology 79:2581-2592

Puotinen ML (2004) Tropical cyclones in the Great Barrier Reef, Australia, 1910-1999: a first step towards characterising the disturbance regime. Aust Geogr Stud 42: 378-392

Shields A (1936) Application of similarity principles and turbulence research to bed-load movement. Mitt Preussischen Versuchsanstalt Wasserbau Schiffbau 26: $5-24$

Sleath JFA (1984) Seabed mechanics. John Wiley \& Sons, New York, NY

Soulsby R (1997) Dynamics of marine sands. Thomas Telford, London

Sousa WP (1984) The role of disturbance in natural communities. Annu Rev Ecol Syst 15:353-391

Svensson JR, Lindegarth M, Siccha M, Lenz M, Molis M, Wahl M, Pavia H (2007) Maximum species richness at intermediate frequencies of disturbance: consistency

Editorial responsibility: Matthias Seaman,

Oldendorf/Luhe, Germany among levels of productivity. Ecology 88:830-838

Thomsen MS, Wernberg T, Kendrick GA (2004) The effect of thallus size, life stage, aggregation, wave exposure and substratum conditions on the forces required to break or dislodge the small kelp Ecklonia radiata. Bot Mar 47: 454-460

Van Woesik R, Ayling AM, Mapstone B (1991) Impact of tropical cyclone 'Ivor' on the Great Barrier Reef, Australia. J Coast Res 7:551-558

> Warwick RM, Uncles RJ (1980) Distribution of benthic macrofauna associations in the Bristol Channel in relation to tidal stress. Mar Ecol Prog Ser 3:97-103

Webb DJ, Cuevas BA, Coward AC (1998) The first main run of the OCCAM global ocean model. Internal Report of James Rennell Division, Southampton Oceanography Centre, Southampton

Whiteway T (2009) Australian bathymetry and topography grid. Geoscience Australia Record 2009/21, Canberra

Williams GD, Bindoff N (2003) Wintertime oceanography of the Adelie Depression. Deep-Sea Res II 50:1373-1392

Wu J, Loucks OL (1995) From balance of nature to hierarchical patch dynamics: a paradigm shift in ecology. Q Rev Biol 70:439-466

Young OR, Osherenko G, Ogden J, Crowder LB and others (2007) Solving the crisis in ocean governance: placebased management of marine ecosystems. Environment 49:20-32

Submitted: June 16, 2011; Accepted: October 24, 2011 Proofs received from author(s): February 27, 2012 